\title{
Manic delirium and frontal-like syndrome with paramedian infarction of the right thalamus
}

\author{
JULIEN BOGOUSSLAVSKY,* MARCO FERRAZZINI,* FRANCO REGLI,* \\ GIL ASSAL,$\dagger$ HIROTAKA TANABE, $\dagger$ ANGELIKA DELALOYE-BISCHOF
}

From the Department of Neurology, ${ }^{*}$ Division of Neuropsychology, $\dagger$ and Division of Nuclear Medicine, $\ddagger$ Centre Hospitalier Universitaire Vaudois, Lausanne, Switzerland

SUMMARY A disinhibition syndrome affecting speech (with logorrhoea, delirium, jokes, laughs, inappropriate comments, extraordinary confabulations), was the main manifestation of a rightsided thalamic infarct involving the dorsomedian nucleus, intralaminar nuclei and medial part of the ventral lateral nucleus. Resolution of conflicting tasks was severely impaired, suggesting frontal lobe dysfunction. These abnormalities correlated with the finding on SPECT of a marked hypoperfusion in the overlying hemisphere predominating in the frontal region. We suggest that this behavioural syndrome was produced by disconnecting the dorsomedian nucleus from the frontal lobe and limbic system.

Unilateral non-haemorrhagic infarcts limited to the non-dominant thalamus are uncommon. Moreover, they may be missed, because they may give rise to non-focal disturbances, such as impairment of consciousness, acute confusional state, or apathy, without major focal neurological or neuropsychological findings. We report a patient with a right thalamic infarct, whose main disturbance was a disinhibition syndrome mainly affecting speech, which mimicked an acute manic delirium. The findings of a marked hypofusion in the overlying hemisphere predominating in the frontal region suggested a cortical deafferentiation due to the thalamic lesion.

\section{Case report}

A 72 year old right-handed housewife was admitted to hospital after she suddenly became somnolent. She never smoked and was not known to be hypertensive. She had no past history of psychiatric illness or stroke. The morning of admission, she was found by her husband on the floor of the bathroom, somnolent and confused. On examination the same day, she was drowsy but easily arousable; she was disoriented in time and place. Blood pressure was $150 / 90 \mathrm{~mm}$

Address for reprint requests: J. Bogousslavsky, MD, Department of Neurology, CHU, 1011 Lausanne, Switzerland.

Received 4 November 1986 and in revised form 27 May 1987. Accepted 1 June 1987.
$\mathrm{Hg}$ with a regular cardiac rhythm $(80 / \mathrm{min})$. Upgaze seemed slightly limited $\left(20^{\circ}\right)$, but the remainder of the cranial nerves were normal. In the limbs, the strength, tone and tendon reflexes were symmetrical and normal. The plantar reflexes were flexor. Tactile, pain, temperature, vibratory and postural sensation was normal. Coordination was normal in all limbs, but the gait was not tested. General examination showed no abnormality. From the day following admission, the patient was not drowsy, but she was still disoriented. She collaborated well with the examiner, but showed spectacular behavioural changes. She remained lying on her bed or sitting on a chair, with constant smiling and inappropriate laughing. Her speech was not dysphasic but she showed a marked logorrhoea, with constant switch from one idea to another. She could start a conversation adequately but, immediately afterwards, her talk became interrupted by inappropriate and fantastic stories: "this morning I had a fight with my honey pancakes, because somebody tried to put a chicken into my stomach; thus I vomited many times my liver"; "my husband had his heart taken out of his chest and thrown into the garbage"; "my prince will be coming this afternoon and he will bring me jewels, so that I can go to Yugoslavia with my husband, my daughter-in-law and the patient in the bed next to me"; "I do not want to be examined by you with your big blue face, your nose is horrible". She also gave nicknames to the staff; for instance, her doctor was "Saint Niklaus" and one of the nurses "Mercury". When the patient next to her was being examined, she made comments and jokes aloud, answering herself the questions put to the other patient. This inappropriate speech could well be transiently inhibited if the examiner asked her 
to be serious and to concentrate, but after a few seconds, the patient again started to laugh and made inappropriate comments. This disinhibited speech contrasted with her behavioural lack of spontaneity: the patient usually stayed in bed or on a chair, without any drive to initiate goal-directed actions. No useful behaviour was observed. Neuropsychological testing showed normal naming, ${ }^{1}$ repetition, ${ }^{1}$ comprehension, ${ }^{2}$ reading, ${ }^{1}$ writing, ${ }^{1}$ facial recognition, ${ }^{1}$ Poppelreuter, ${ }^{3}$ topographic orientation on maps, ${ }^{1}$ cube drawing. Copy of the Rey-Osterrieth figure ${ }^{4}$ showed decreased precision in the left part of the figure. No series could be realised in the Wisconsin Card Sorting test. ${ }^{5}$ There were difficulties in inhibiting automatic responses during conflicting tasks $^{67}$ (Strooptest $^{6}$ : slowed (2'), 12 mistakes, 2 self-corrections) and moderate disturbances of non-verbal memory (10 signs of $R_{e y}^{4}$ : 2-2-5). The Raven pM-38 showed good results (17, corrected for age and socio-cultural factors: 33 , percentile 75 ). There was no extinction on simultaneous bilateral visual or tactile (face, arm or leg) stimulation. The neurological examination was checked several times, and showed no new finding.

CT on the day of admission showed an old lacune (largest diameter: $5 \mathrm{~mm}$ ) in the head of the caudate nucleus on the left and a slightly hypodense area in the right paramedian thalamus (fig la). One week later, this hypodense area was better defined, suggesting a recent infarct (fig lb). Transverse and sagittal slices centred on the infarct (fig lb) suggested involvement of the intralaminar nuclei (including the centromedian nucleus), the dorsomedian nucleus, and the most internal part of the ventral lateral nucleus. An EEG 2 days after admission showed a moderate bradydysrhythmia over the anterior regions, predominating on the right. A SPECT using N-isopropyl-(I-123)-p-iodoamphetamine 10 days after admission showed a marked hypoperfusion in the right thalamic region (decrease of $50 \%$ compared with the left side), with an associated hypoperfusion of the overlying cortex, mainly in the frontal region (decrease of $30 \%$ compared with the left side) (fig 2). Extracranial Doppler ultrasound studies were normal. A lumber puncture revealed normal CSF. A chest radiograph, ECG, and standard blood and urine tests were normal.

Two months later, the disinhibition of the patient had improved and she could lead a simple conversation with only occasional interruptions by inappropriate comments and laughs. Six months later, the patient had further improved, being able to perform tests which were previously impossible for her to perform (Wisconsin card sorting test: ${ }^{5} 3$ series).

\section{Discussion}

In this patient without significant neurological findings, transient drowsiness was followed by a persisting disinhibition syndrome mainly affecting speech, with a manic-like logorrhoea, laughs and inappropriate jokes. There was difficulty in inhibiting automatic tasks which were disabling, but other disturbances were less severe, being limited to nonverbal memory and visuospatial processing. CT disclosed a recent right thalamic infarct in the posterior thalamo-subthalamic paramedian artery territory, ${ }^{910}$ involving mainly the intralaminar nuclei and the dorsomedian nucleus. No pathological confirmation was available, but recent evidence ${ }^{11}$ suggests that involvement of thalamic nuclear groups from nonhaemorrhagic infarction can be accurately assessed by CT.

Unilateral infarction of the non-dominant thalamus is uncommon, and we found only 17 cases with

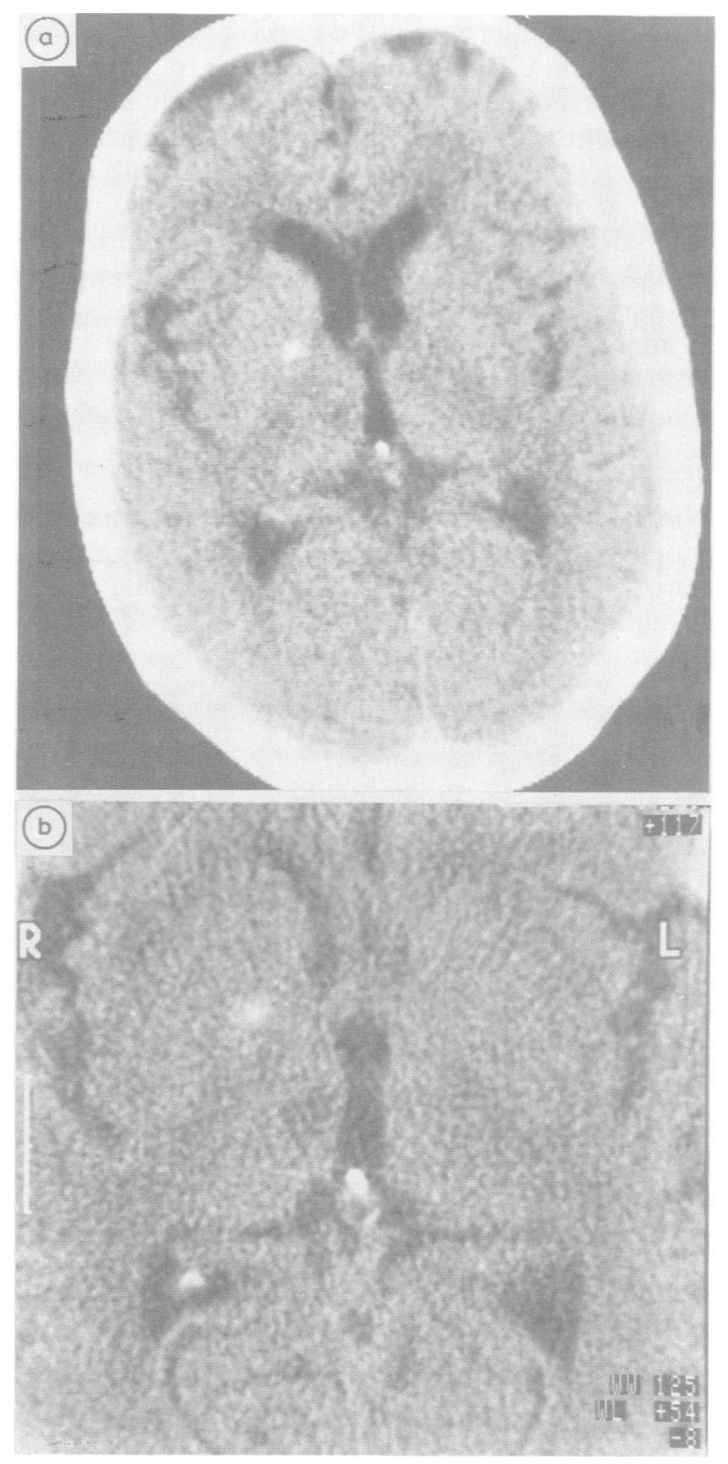

Fig 1 CT scan (a) on the day of admission: hazy hypodense area in the paramedian part of the right thalamus, calcification in the right globus pallidus; (b) 2 weeks later: better demarcation of the thalamic hypodense area; magnification suggests involvement of the dorsomedian nucleus, intralaminar nuclei, and medial part of the ventral lateral nucleus. 
a clinico-anatomic study (necropsy: 12 ; CT: 5 ) in the literature. ${ }^{12-26}$ In the early clinico-pathologic reports, no behavioural or neuropsychological disturbances were mentioned, and there is only one necropsy case with a detailed neuropsychological examination. ${ }^{19}$ One of the main problems arising when trying to analyse these clinico-pathologic reports is the universal presence of associated lesions. Although small lesions later revealed by necropsy or MRI may be missed on CT, large infarcts similar to those found in the necropsied cases were reliably excluded.

Overall, four types of neuropsychological dysfunction were reported in those patients with a right thalamic infarct: hemineglect, ${ }^{19}{ }^{21}$ which may be associated with anosognosia and asomatognosia, mimicking a parietal lobe dysfunction, ${ }^{21}$ impaired memory for non-verbal material, ${ }^{23}{ }^{26}$ apathy and disinterest, with lack of initiative and often anosognosia, ${ }^{20}{ }^{24}$ acute confusional state. ${ }^{25}$ These abnormalities usually coexisted, ${ }^{202426}$ but each may be the sole or predominant dysfunction. ${ }^{20} 212325$ A manic-like state was not reported.

In many ways, our patient looked very much like patients with extensive medial right prefrontal damage, ${ }^{727}$ who show speech (less often behavioural) disinhibition, with "fuite des idées" and loss of

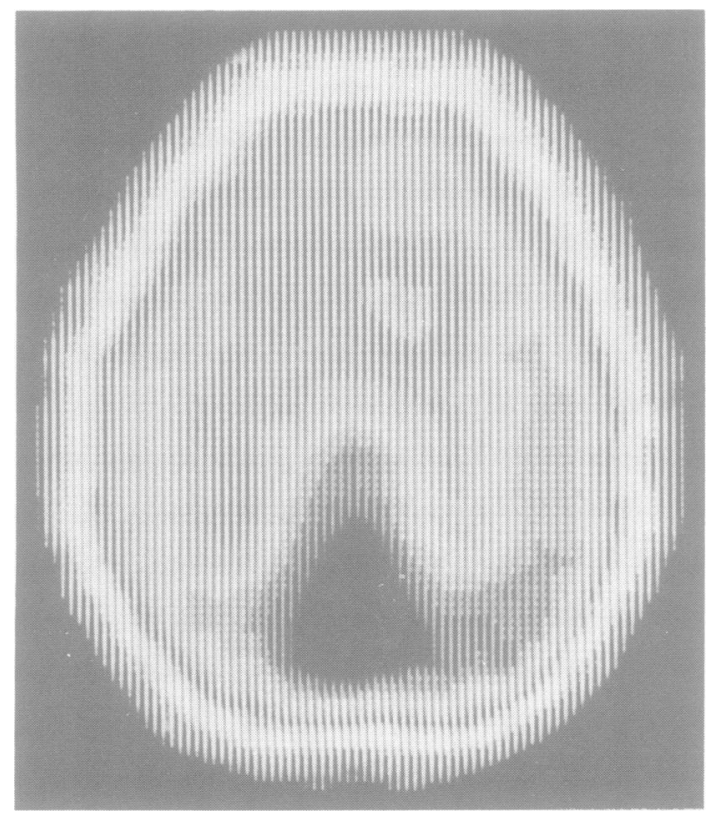

Fig 2 SPECT using N-isopropyl-(I 123)-p-iodoamphetamine (10 days after stroke): at 10 minutes, marked hypoperfusion (50\% compared with the left side) in the right thalamic region, with an associated perfusion decrease in the overlying hemisphere, predominating in the frontal region $(30 \%)$. selectivity of the mental processes. ${ }^{7}$ As in such lesions and in lesions involving the dorsolateral part of the prefrontal region, ${ }^{27} 28$ our patient showed difficulty in performing conflicting tasks and inhibiting automatic responses in the Wisconsin Card Sorting, Stroop's, and Luria's tests. "Extraordinary" confabulations have also been reported in frontal lobe damage..$^{29} 30$ Frontal lobe signs on testing were present in the patient reported by Speedie and Heilman, ${ }^{23}$ who had involvement of the dorsomedian nucleus on CT. These authors emphasised the involvement of the connections between the magnocellular part of the dorsomedian nucleus and the frontal lobe. In fact, experimental lesions of the internal part of the dorsomedian nucleus in the rat may produce a "frontal lobe syndrome", with disinhibition, loss of selectivity, and perseverations. ${ }^{31}$ With respect to dorsomedian nucleus-frontal lobe connections, it must be emphasised that in our patient, SPECT showed a marked decrease of cerebral blood flow not only in the right thalamic region, but also in the overlying hemisphere, mainly in the frontal region. One previously reported patient with a paramedian right thalamic infarct and apathy, lack of initiative and irritability had a significant decrease of $\mathrm{CBF}$ and metabolism in the ipsilateral frontal lobe on PET. ${ }^{26}$ Baron et $\mathrm{al}^{32}$ reported cortical hypometabolism on PET in nine of 10 patients with ipsilateral thalamic vascular lesions, suggesting cortical deafferentiation; no cortical hypometabolism was found in another patient, who was the only one of the 10 not to have neuropsychological dysfunction. These findings must be interpreted with caution, as diaschisis does not always have a clinicalo counterpart. However, it is possible that the lesion of the dorsomedian nucleus in our patient was responsible for dysfunction of the ipsilateral frontal lobe, with the subsequent production of a frontal-like syndrome. Involvement of the connections between the dorsomedian nucleus and the amygdala and other parts of the limbic system ${ }^{33} 34$ may also have played a role in the genesis of the disinhibiting syndrome.

\section{References}

1 Assal G. Batterie des Examens Neuropsychologiques du CHUV. Lausanne, Centre Hospitalier Universitaire Vaudois, 1985.

2 De Renzi E, Vignolo LA. The Token test: a sensitive test to detect receptive disturbances in aphasia. Brain 1962. 85:665-78.

3 Poppelreuter W. Die psychischen Schädigungen durch Kopfschuss im Kriege 1914/16. Leipzig, Von Leopold Voss, 1917.

4 Rey A. L'Examen Clinique en Psychologie. Paris, PUF, 1965.

5 Berg EA. A simple objective test for measuring flexibility in thinking. J Gen Psychol 1948;39:15-22.

6 Stroop JR. Studies of interference in serial verbal reactions. $J$ Exp Psychol 1945;18:643-62.

7 Luria AR. Frontal lobe syndromes. In: Vinken PJ, Bruyn GW (eds): Handbook of Clinical Neurology, vol 2 Amsterdam, Elsevier 1969, 725-57.

8 Raven JC. Guide to the Standard Progressive Matrices. London, HK Lewis, 1960 
9 Percheron G. Les arêtes du thalamus humain. II. Artères et territoires thalamiques paramédians de l'artère basilaire communicante. Rev Neurol (Paris) 1976;132:309-24.

10 Schlesinger B. The upper Brainstem in the Human: its Nuclear Configuration and Vascular Supply. New York Springer, 1976.

11 Graff-Radford NR, Schelper RL, Ilinsky IA, Damasio H. CT and postmortem study of a nonhemorrhagic thalamic infarction. Arch Neurol 1985;42:761-3.

12 Sigwald J, Monnier M. Syndrome thalamo-hypothalamique avec hémitremblement (ramollissement du territoire artériel thalamo-perforé). Rev Neurol 1936;66:616-631.

13 Schuster P. Beiträge zur Pathologie des Thalamus Opticus. I. Mitteilung: Kasuistik. Gefässgebiet der A. thalamo-geniculata, $\operatorname{der} \mathbf{A}$ thalamo-perforata, der A tubero-thalamica und der A lenticulo-optica. Arch Psychiat Nervenkrank 1936;105: 358-432.

14 Kleist K, Gonzalo J. Über Thalamus-und Susthalamussyndrome und die Störungen einzelner Thalamuskerne. Monatsschr Psychiat Neurol 1938;99:87-130.

15 Gruner JE, Feuerstein J. Troubles de la conscience et tronc cérébral. Corrélations anatomo-cliniques. In Juhāsz IL (ed), Clinical experiences in brain stem disorders (Acta 25 Conventus Neuropsychiatricus et EEG Hungarici), Budapest Vällalat 1966 , 293-296.

16 Jakimowicz W, Stefanko A, Pajak B. Ramollissements du thalamus dans le territoire des pédicules artériels venant de la cérébrale postérieure. Acta med Pol 1968;9:447-454.

17 Garcin R, Lapresle J. Incoordination cérébelleuse du membre inférieur par lésion localisée dans la région interne du thalamus contralatéral. Rev Neurol 1969;120:5-13.

18 Sieben G, de Reuck J, Vander Eecken H. Thrombosis of the mesencephalic artey. A clinico-pathological study of 2 cases and its correlation with the arterial vascularization. Acta neurol Belg 1977;77:151-162.

19 Cambier J, Elghozi D, Strube E. Lésions du thalamus droit avec syndrome de l'hémisphère mineur. Discussion du concept de négligence thalamique. Rev Neurol (Paris) 1980;136:105-16.

20 Castaigne P, Lhermitte F, Buge A, Escourolle R, Hauw JJ, Lyon-Caen $\mathrm{O}$. Paramedian thalamic and midbrain infarcts: clinical and neuropathological study. Ann Neurol 1981;10: $127-48$.

21 Watson RT, Valenstein E, Heilman KM. Thalamic neglect. Pos- sible role of the medial thalamus and nucleus reticularis in behaviour. Arch Neurol 1981;38:501-6.

22 Pierrot-Deseilligny C, Chain F, Gray F. Parinaud's syndrome. Electro-oculographic and anatomical analyses of six vascular cases with deduction about vertical gaze organization in the premotor structures. Brain 1982;105:667-96.

23 Speedie LJ, Heilman KM. Anterograde memory deficit for visuospatial material after infarction of the right thalamus. Arch Neurol 1983;40:183-6.

24 Bogousslavsky J, Regli F. Upgaze palsy and monocular paresis of downward gaze from ipsilateral thalamo-mesencephalic infarction: a vertical "one-and-a-half-" syndrome. J Neurol 1984;231:43-45.

25 Friedman JH. Syndrome of diffuse encephalopathy due to nondominant thalamic infarction. Neurology 1985;35:1524-6.

26 Franck G, Salmon E, Sadzot B, Van der Linden M. Etude hémodynamique et métabolique par tomographie à émission de positrons d'un cas d'atteinte ischémique thalamo-capsulaire droite. Rev Neurol (Paris) 1986;142:475-9.

27 Eslinger PJ, Damasio AR. Severe disturbance of higher cognition after bilateral frontal lobe ablation: Patient EVR. Neurology 1985;35:1731-41.

28 Milner B. Some effects of frontal lobectomy in man. In: Warren JM, Akert K, eds. The Frontal Granular Cortex and Behaviour. New York, McGraw Hill 1964, 313-34.

29 Stuss DT, Alexander MP, Libierman A, Levine H: An extraordinary form of confabulation. Neurology 1978;28:1166-71.

30 Kapur N, Coughlan: Confabulation and frontal lobe dysfunction. J Neurol Neurosurg Psychiatry 1980;43:461-3.

31 Kolb B. Studies on the caudate-putamen and the dorsomedial thalamic nucleus of the rat: implications for mammalian frontal-lobe functions. Physiol Behav 1977;37:237-44.

32 Baron JC, D'Antona R, Serdaru M, Pantano P, Bousser MG, Samson Y. Hypométabolisme cortical après lésion thalamique chez l'homme. Etude par la tomographie à positrons. Rev Neurol (Paris) 1986;142:465-74.

33 Yakovlev PI. Motility, behavior and the brain. Stereodynamic organization and neural coordinates of behavior. J Nerv Ment Dis 1948;107:313-35.

34 Nauta WJH. Neural associations of the amygdaloid complex in the monkey. Brain 1962;85:505-20. 